\title{
Quantitative assessment of neural elements in a rat model using nerve growth factor after remnant-preserving anterior cruciate ligament reconstruction: a histological and immunofluorescence pilot study
}

\author{
Sung Hyun Lee ${ }^{1}$, Hyung Gyu Cho' ${ }^{1}$ Jin Soo Song ${ }^{2}$, Keun Churl Chun ${ }^{3}$ and Churl Hong Chun ${ }^{1 *}$ (D)
}

\begin{abstract}
Background: Immunofluorescence analyses of anterior cruciate ligament (ACL) allografts following remnantpreserving $A C L$ reconstruction using Achilles tendon allografts have provided evidence for the presence of neural elements. In this study, we aimed to examine the expression of neural elements and quantify the presence of neural cells in ACL remnants and Achilles allografts using nerve growth factor (NGF) therapy after remnantpreserving $A C L$ reconstruction.

Methods: Experiments were conducted on 5 pairs of rats (approximately 8 weeks old and weighing $320 \mathrm{~g}$ at the time of surgery). Longitudinally, split Achilles tendons from the paired rats were freshly frozen and later defrosted with warm saline and allografted onto the right $A C L$ of the other rat that was partially detached at the femoral attachment site. A sham operation was conducted on the left knee to be used as a control. NGF was injected into both knee joints every week for 6 weeks after surgery. The presence of neural cells in the ACL of the sham-operated knee, allografted Achilles tendon, and $\mathrm{ACL}$ remnant was examined 6 weeks post-surgery using $\mathrm{H}$ and $\mathrm{E}$ and immunofluorescent staining.

Results: $\mathrm{H}$ and $\mathrm{E}$ staining did not reveal neural cells in any of the three groups. However, immunofluorescence analysis showed the presence of nestin-positive neural elements in the normal ACL tissues as well as ACL remnants. Additionally, neural elements were examined in 7 of the 8 (87.5\%) allograft tissues. Quantitative analysis showed no difference in the number or area of nuclei among the three groups. However, the number and area of neural cells in the Achilles allografts were significantly lower than those in the other two groups ( $p=0.000$ and $p=0.001$, respectively).

*Correspondence: cch@wonkwang.ac.kr

'Department of Orthopedic Surgery, Wonkwang University Hospital, 895,

Muwang-Ro, Iksan 54538, South Korea

Full list of author information is available at the end of the article

(c) The Author(s). 2020 Open Access This article is licensed under a Creative Commons Attribution 4.0 International License, which permits use, sharing, adaptation, distribution and reproduction in any medium or format, as long as you give appropriate credit to the original author(s) and the source, provide a link to the Creative Commons licence, and indicate if changes were made. The images or other third party material in this article are included in the article's Creative Commons licence, unless indicated otherwise in a credit line to the material. If material is not included in the article's Creative Commons licence and your intended use is not permitted by statutory regulation or exceeds the permitted use, you will need to obtain permission directly from the copyright holder. To view a copy of this licence, visit http://creativecommons.org/licenses/by/4.0/ The Creative Commons Public Domain Dedication waiver (http://creativecommons.org/publicdomain/zero/1.0/) applies to the data made available in this article, unless otherwise stated in a credit line to the data. 
(Continued from previous page)

Conclusion: Our observations indicate that ACL remnants promote the new ingrowth and persistence of neural cells. We suggest that the ingrowth of neural elements can support the persistence and new ingrowth of mechanoreceptors, thereby enhancing the functional stability of knee joints. Moreover, the expression of neural cells in the Achilles allografts was lower than that in normal ACL tissues and ACL remnants in the quantitative evaluation, thereby confirming the essential role of ACL remnants in knee joint functionalization.

Keywords: Anterior cruciate ligament, Remnant preservation, Immunofluorescence, Nerve growth factor

\section{Background}

The functional instability of a knee joint is primarily caused by the lack of coordinated muscle stabilization, thereby inciting pertinent interest in unravelling methods to protect mechanoreceptors in the knee joint $[1,2]$. It has been reported that the remnant-preserving ACL reconstruction technique preserves mechanoreceptors and renders positive results [1,3-7]. The current study aimed to determine whether the remnant preservation technique preserves the existing mechanoreceptors or leads to re-innervation.

Evidence has demonstrated the growth of mechanoreceptors in reconstructed ACLs. For instance, Barrack et al. reported an increase in mechanoreceptors in ACL grafts in dogs 6 months after surgery compared to their normal patellar tendon [8]. Denti et al. reported that mechanoreceptors were present in the bone-patellar tendon autografts in the knees of sheep 3 months after surgery and in human knees with failed autografts at 9 and 10 years after surgery [9]. These findings suggest that ACL remnants are a possible source of re-innervation of the tendon graft. However, previous histological studies have failed to validate the presence of mechanoreceptors in ACL allografts [10]. In addition, few studies have quantitatively evaluated neural elements in ACL remnants and ACL allografts.

Nerve growth factor (NGF) is widely used clinically for its significant roles in supporting neuronal survival, peripheral nerve growth, nutritional adaptation, nerve regeneration, and fracture repair [11]. However, it has not been delineated whether these receptors affect reinnervation or proprioception. However, the persistence of mechanoreceptors after remnant-preserving ACL reconstruction is important. Thus, by stimulating the expression of neural cells using NGF, we tried to validate the superiority of the remnant preservation technique.

The aim of the present study was to investigate the effects of administering NGF following the remnant preservation technique by assessing the presence of nerve cells via immunofluorescence in the allograft and remnant ACL. In addition, neural elements in ACL remnants and ACL allografts were quantitatively evaluated using ImageJ particle analysis. We hypothesized that remnant tissues following ACL reconstruction as well as Achilles allografts would contain neural cells, which were identified using immunofluorescence.

\section{Methods}

\section{Animals}

Experiments were conducted on 10 adult male rats (Rattus norvegicus albinus, Samtako ${ }^{\oplus}$, Korea) that were approximately 8 weeks old and weighed $320 \mathrm{~g}$ at the time of surgery. All the rats were numbered using ear tags. The rats were housed in accordance with the National Institutes of Health guidelines; they were kept in a vivarium, maintained at $20-25^{\circ} \mathrm{C}$ and $60 \%$ humidity with 12 $\mathrm{h}$ alternating light-dark cycles $(7 \mathrm{am}-7 \mathrm{pm})$, and were provided food and water ad libitum.

\section{Surgical procedure The remnant-preserving ACL allograft}

Arthrotomy was performed after intraperitoneal (IP) administration of general anaesthesia [a mixture of Zoletil (50 mg/kg, Virbac Laboratories, France) and Rompun (10 mg/kg, Bayer, Korea)]. In pairs, the Achilles tendon was obtained from a donor rat and used as an allograft for ACL reconstruction in the right knee of the recipient rat. Briefly, an approximately $1.5 \mathrm{~cm}$ longitudinal skin incision was made on the Achilles tendon insertion site in the left ankle. After longitudinally splitting $1.5 \mathrm{~cm}$ of the Achilles tendons of each rat, the tissue was fresh frozen at $-80^{\circ} \mathrm{C}$ for $5 \mathrm{~min}$ in a deep freezer. Then, the Achilles tendon was defrosted with $47^{\circ} \mathrm{C}$ warm saline for $5 \mathrm{~min}$ (Fig. 1) and used as an allograft.

For the ACL reconstruction, an approximately $1.5-\mathrm{cm}$ incision was made on the right knee. Then, the joint was exposed by transposing the patella laterally after a parapatellar incision was made with the knee in flexion. The ACL was detached at the femoral insertion, but the tibial insertion was maintained. Subsequently, the Achilles tendon was allografted onto the right ACL, which was partially detached at the femoral attachment site. Suture fixation was used on the femoral and tibial ACL anatomical attached sites (Fig. 2). Irrigation was performed on the joints, and the capsule and skin were closed with interrupted sutures. 

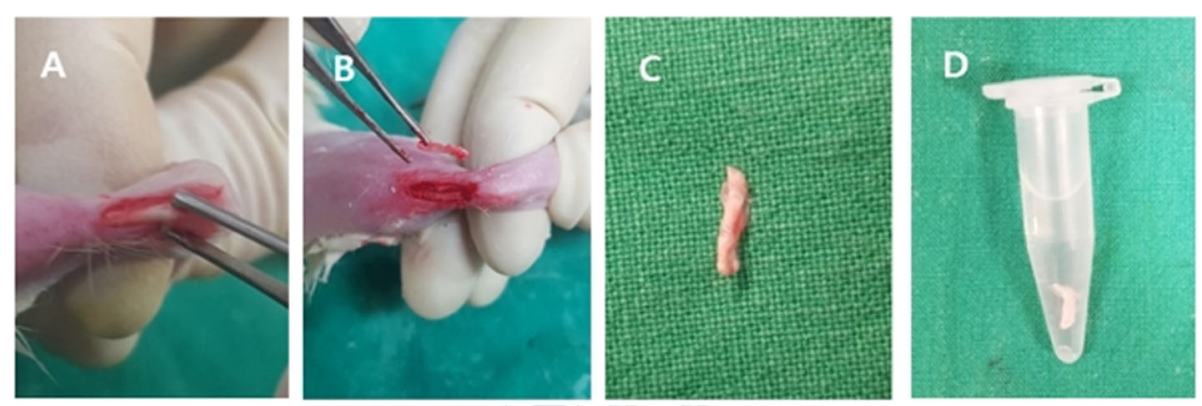

Fig. 1 Achilles tendon was grafted for ACL reconstruction. a Achilles tendon exposure. b, c Split Achilles tendon. d Frozen Achilles tendon thawing in warm saline $\left(47^{\circ} \mathrm{C}\right.$ for $\left.5 \mathrm{~min}\right)$

\section{The sham operation}

A sham operation was conducted on the left knee as a control. The knee joints were exposed with the same incision. Additionally, irrigation was performed on the joints, and the capsule and skin were closed with interrupted sutures.

\section{NGF injection and sample collection}

A total of $10 \mu \mathrm{l}$ of recombinant rat NGF $(50 \mu \mathrm{g}$ dissolved

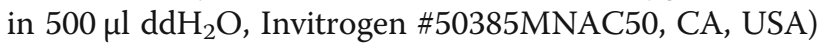
was injected into both knee joints every week for 6 weeks after the operation using a 0.3 -cc insulin syringe with a microfine needle. The presence of neural cells in the control group (sham operation), allografted Achilles tendon, and ACL remnants was examined 6 weeks postsurgery using haematoxylin and eosin ( $\mathrm{H}$ and $\mathrm{E})$ staining and immunofluorescent staining with anti-nestin antibody. The presence of neural cells was then compared among the Achilles allografts, ACL remnants, and normal ACL (sham operation) tissues.

\section{$\mathrm{H}$ and $\mathrm{E}$ staining}

Tissue samples were collected from the femoral insertion site of normal ACL tissues, the detached site of ACL remnants and the femoral insertion site of Achilles allografts. After dehydration with alcohol and washing with a tissue processor (Leica TP 1020, Leica, Germany), tissue pieces were fixed with masked formalin solution (mask form 2A, DANA Korea) for $24 \mathrm{~h}$ and embedded in paraffin. The tissues were sectioned sequentially into $4 \mu \mathrm{m}$ thick slices and stained with $\mathrm{H}$ and $\mathrm{E}$. Mechanoreceptors were classified into four types according to a prior study (type I, a spherical or ovoid Ruffini corpuscle; type II, a columnar concentric circular Pacini corpuscle; type III, a spindleshaped Golgi corpuscle; and type IV, a non-myelinated free nerve ending) [12]. Sections with $\mathrm{H}$ and $\mathrm{E}$ staining were assessed for the presence of mechanoreceptors following the stated classification.

\section{Immunofluorescent staining}

Sliced tissues on coverslips were washed three times with phosphate-buffered saline (PBS), fixed with $4 \%$
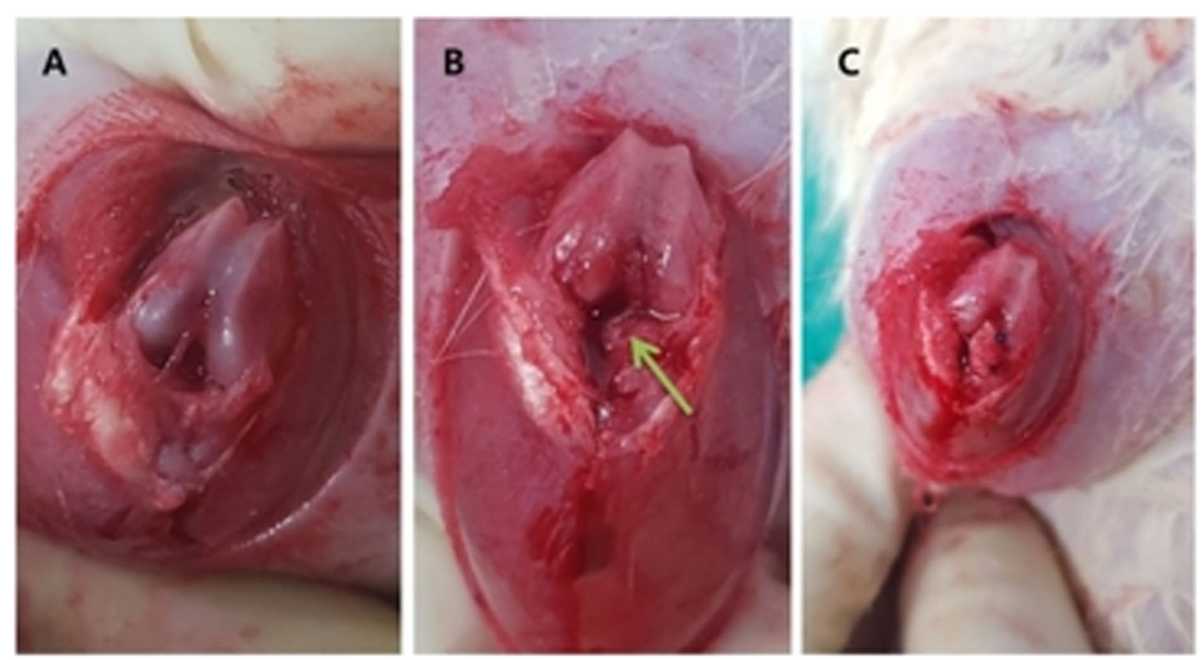

Fig. 2 Achilles tendon was allografted to each rat's left ACL. a ACL exposed. b ACL partially detached (green arrow). c Achilles tendon grafted to the ACL 
paraformaldehyde in PBS for $10 \mathrm{~min}$, and permeabilized with $0.1 \%$ Triton $\mathrm{X}-100$ in PBS for $5 \mathrm{~min}$ at room temperature. After washing three times with PBS, sections were blocked with $1 \%$ bovine serum albumin (BSA) for $1 \mathrm{~h}$ at room temperature. Sections were incubated with anti-nestin antibody (N5413, Sigma-Aldrich, St. Louis, MO) (diluted in blocking solution (1\% BSA in PBS)) for $1 \mathrm{~h}$ at room temperature in a shading box. Subsequently, the tissue sections were washed three times with PBS and incubated with secondary antibody, Alexa Fluor 555-conjugated rabbit anti-goat antibody (Invitrogen, Grand Island, NY) for $1 \mathrm{~h}$ at room temperature. Alexa Fluor 488-conjugated phalloidin (Invitrogen, Grand Island, NY) was used for F-actin staining. Nuclei were stained with 4,6-diamidino-2-phenylindole (DAPI, Santa Cruz Biotechnologies, Santa Cruz, CA). Images were captured using a confocal microscope (Olympus, FV-1 mm).

\section{Quantification with particle analysis}

After immunofluorescent staining, quantitative analysis was performed on each image using ImageJ (National Institutes of Health, Bethesda, MD). The number and area of nuclei that were stained with DAPI and the neural cells that were stained with anti-nestin antibody were calculated. Several attached cells in each image were optically separated using a watershed separation tool provided by the ImageJ software. Following this, the area and number of cells were quantified using ImageJ particle analysis.

\section{Statistical analysis}

Statistical analysis was conducted using SPSS for Windows, version 12.0. The Kruskal-Wallis test was used to analyse the immunofluorescence data (with the $95 \%$ confidence level). $P$ values $<0.05$ were considered significant. Where indicated, Mann-Whitney post hoc analysis was performed after the Kruskal-Wallis test, with a significance level set at $p<0.16$. The power of group comparison was analysed using G*Power 3.1.9.2, where this study achieved a power of 0.68 for detecting differences with $\alpha=0.05$.

\section{Results}

Two of 10 rats expired during the experiment (at 2 weeks and 4 weeks post-surgery). The experiment was completed with the remaining 8 rats.

$\mathrm{H}$ and $\mathrm{E}$ examination confirmed ligamentous ACL tissues and synovium in all the sections (Fig. 3). However, neural cells or mechanoreceptors could not be detected in normal ACL tissues, ACL remnants, or Achilles allograft tissues through $\mathrm{H}$ and $\mathrm{E}$ staining (Fig. 3).

In the immunofluorescence study, nestin was expressed in all normal ACL tissues that were injected with NGF. In addition, nestin was expressed in all ACL remnants and in 7 of $8(87.5 \%)$ allograft tissues that were processed with NGF (Table 1). Nestin-positive cells suggested the possible presence of neural cells in the ACL remnant tissue and Achilles allografts (Fig. 4). We did not observe any significant difference in neural cell expression among the normal ACL tissues, ACL remnants, and Achilles allografts within the immunofluorescence study $(p=0.368)$.

Quantitative analysis showed no difference in the number and area of nuclei among normal ACL tissues, ACL remnants, and Achilles allografts. However, the number and area of neural cells were significantly different among the groups. Post hoc analysis revealed that the number and area of neural cells in Achilles allografts were smaller than those in normal and remnant ACL tissues $(p=0.000$ and $p=0.001$, respectively) (Table 2) (Fig. 5).

\section{Discussion}

This study used immunofluorescence analysis to shed light on a critical aspect of the localization of neural elements. We provide evidence that neural elements are found in not only remnant ACL tissues but also Achilles allografts. In the quantitative test, the neural cells of ACL remnants were not found to be different from those of normal ACL tissues. These results indirectly demonstrate that ACL reconstruction with remnant preservation can better preserve proprioception and be a resource for re-innervation in reconstructed allografts.

Proprioception is a key factor in maintaining the stability of the knee joint against functional deficiencies
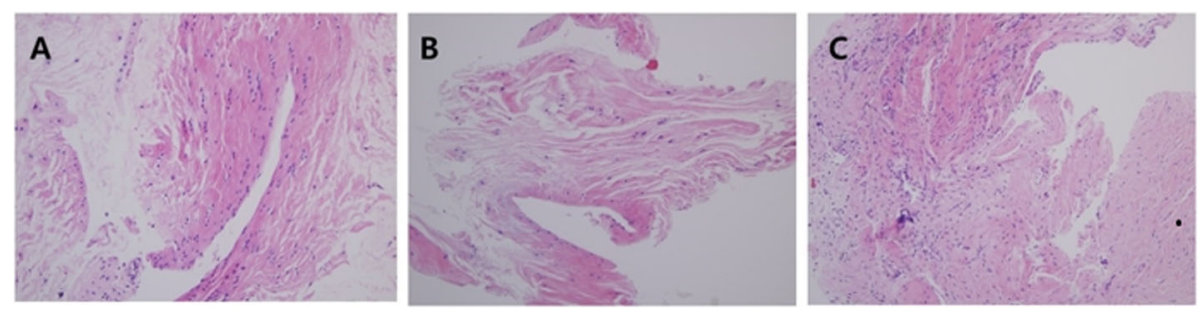

Fig. 3 In all cases, no mechanoreceptors were present on $\mathrm{H}$ and E staining. a Normal ACL (control specimen). b Remnant ACL specimens. c Achilles allograft specimens ( $H$ and $E$ stain, $\times 20)$ 
Table 1 Immunofluorescence study on the presence of nestin-positive neural cells

\begin{tabular}{llll}
\hline Number & \multicolumn{2}{l}{ Presence of neural cells (nestin staining) } & \\
\cline { 2 - 4 } & Normal ACL (sham operation) & Remnant ACL & Achilles allograft \\
\hline$\# 1$ & + & + & + \\
$\# 2$ & + & + & + \\
$\# 3$ & + & + & + \\
$\# 4$ & + & + & + \\
$\# 5$ & + & + & - \\
$\# 6$ & + & + & + \\
$\# 7$ & + & + & + \\
$\# 8$ & + & & + \\
\hline
\end{tabular}

+expression of nestin

-no expression of nestin

after ACL reconstruction. Many mechanoreceptors known to be distributed in ACL and remnant tissues contribute to the proprioceptive function of the knee $[13,14]$. Some previous studies have reported the presence of mechanoreceptors in ACL remnants after ACL reconstruction with the remnant preservation technique [5, 15-17]. A previous study reported the presence of mechanoreceptors in ACL remnants 3 years after ACL rupture [17]. In another recent study, normal proprioceptive fibres and mechanoreceptors were reported in $50 \%$ of remnant ACL tissues using neurofilament protein staining [16]. They also showed a difference between mechanoreceptors in healthy and injured ACLs and highlighted their clinical significance [15]. Lee et al. reported the presence of mechanoreceptors in approximately one third of ACL remnants, which was less than expected [5]. In this study, neural cells were identified in ACL remnants, which was not different from normal ACL tissues upon quantitative evaluation. This outcome suggests that remnant-preserving ACL reconstruction can preserve proprioception and have a positive effect on knee joint functions.

Conversely, few studies have suggested the possibility that ACL remnants can serve as a source of reinnervation for reconstructed allografts. Ochi et al. stressed that restoring knee function is important in

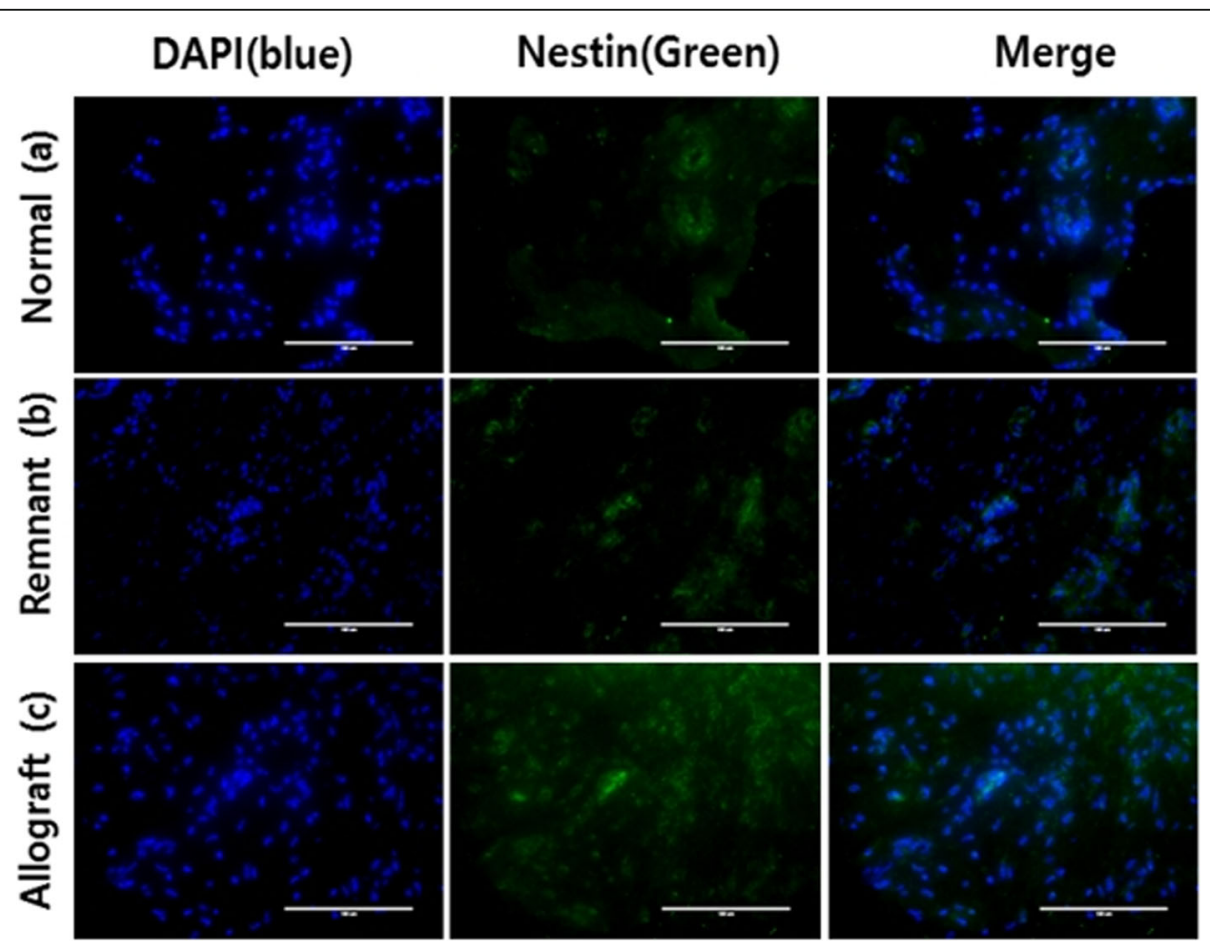

Fig. 4 Immunohistochemical findings of nerve cells. Nuclei were stained with 4,6-diamidino-2-phenylindole (DAPI, Santa Cruz Biotechnologies, Santa Cruz, CA). Nerve cells were stained with anti-nestin antibody in a normal ACL tissues, $\mathbf{b}$ remnant ACL specimens, and $\mathbf{c}$ Achilles allograft specimens 
Table 2 Number and area of nuclei and neural cells in normal, remnant, and allografted ACL tissues

\begin{tabular}{llllll}
\hline & & Normal ACL $(n=8)$ & Remnant ACL $(n=8)$ & Achilles allograft $(n=8)$ & $p$ \\
\hline Nuclei & Number & $178.6 \pm 84.3$ & $114.4 \pm 49.8$ & $179.3 \pm 78.7$ & 0.227 \\
& Area (pixels) & $77565.9 \pm 56207.1$ & $41082.9 \pm 24237.0$ & $76713.6 \pm 37395.3$ & 0.138 \\
Neural cell & Number & $1977.3 \pm 1521.8$ & $1668.5 \pm 1015.6$ & $89.9 \pm 68.8$ & 0.000 \\
& Area (pixels) & $36218.9 \pm 33157.0$ & $29613.4 \pm 21547.3$ & $1846.1 \pm 1179.4$ & 0.001 \\
\hline
\end{tabular}

Data are presented as the mean \pm SD

terms of anatomical ACL reconstruction, and that mechanical restraint and graft sensory re-innervation could potentially improve the overall outcome [18]. Denti et al. found re-innervation of autologous bone-patellar tendonbone grafts in animals 3-6 months after surgery [9]. However, few studies have suggested the possibility that ACL remnants can serve as a source of re-innervation for reconstructed allografts. Kim et al. proposed that no new ingrown mechanoreceptors are present in Achilles allografts [10]. In addition, Chun et al. suggested that Achilles allograft ligaments do not show similar findings compared with biopsy samples from normal ACL tissues [19]. Recently, Chun et al. identified the presence of neural elements in ACL remnant tissues after remnant-preserving ACL reconstruction using immunofluorescence evaluation with NGF application. However, in their study, neural elements were not observed in Achilles allograft tissues [20]. Therefore, we investigated the expression of mechanoreceptors in remnant tissues and allografts following remnant-preserving ACL reconstruction using NGF therapy. In the present animal study, the presence of neural elements was confirmed in remnant tissues and allografts using immunofluorescence methods with NGF, a wellknown growth factor for nerve cell proliferation.

The presence of neural cells in Achilles allografts supports the potential regeneration of neural elements during remnant-preserving ACL reconstruction. This was, however, not supported in previous studies [10, 19].

Many studies have evaluated proprioception, as well as the function of mechanoreceptors in reconstructed ACLs [5, 10, 13-17]. However, it is difficult to compare outcomes between these studies because of variations in the experimental methods and other external factors. Recently, immunofluorescence and immunohistochemistry using specific antigenantibody reactions have been used to detect nerve fibres, producing more reliable and relevant results [5]. In this study, we visualized mechanoreceptor-positive cells using immunofluorescence assessments with monoclonal antibodies against

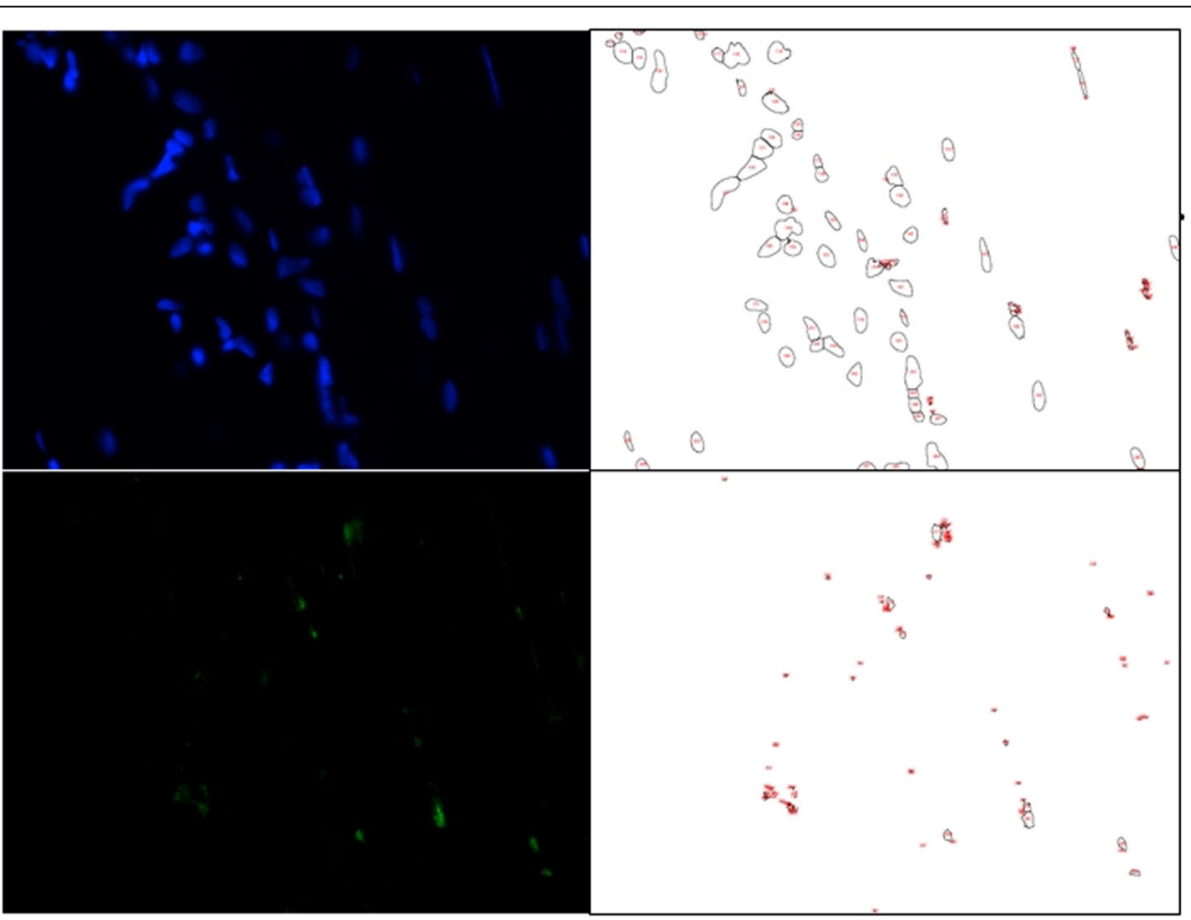

Fig. 5 Several attached cells in each image were separated using the watershed separation tool based on the ImageJ software. Then, the area or number of cells was measured with ImageJ particle analysis 
nestin. To identify the presence of nestin-positive cells in the remnant tissues, the cells were treated in vivo with NGF, which is an important factor in the growth and maintenance of sensory and sympathetic neurons. Previous studies have reported that NGF application can be used to promote the healing of ACLs [21]. They proposed that NGF promoted re-innervation and angiogenesis in the healing of rat ACLs. Therefore, we evaluated the expression of mechanoreceptors in remnant tissues and allografts after remnant-preserving ACL reconstruction using in vivo administration of NGF in rats. The results of the current study indicate that NGF promotes re-innervation of Achilles allografts.

Few studies have attempted to quantify the proprioceptive potential of the injured ACL stump [9, 16, 17]. However, none of these studies have quantified their immunofluorescence findings. We analysed the number and area of nuclei and neural cells that were each stained with DAPI and anti-nestin antibody. The expression of neural cells in the Achilles allograft was less than that in normal ACL tissues and ACL remnants in the quantitative evaluation, although nerve growth was promoted by NGF.

There has been controversy regarding whether the superiority of remnant-preserving ACL reconstruction observed in immunofluorescence and immunohistochemical studies on proprioception can also be observed in terms of clinical function [20]. Some previous studies have reported that the remnant-preserving technique does not show more clearly favourable improvement in clinical outcomes than non-remnant-preserving techniques [22, 23]. In another recent study on a different ligament, there were also no significant differences in the management of chronic lateral ankle instability using a semitendinosus tendon autograft regardless of preservation of the remnant anterior talofibular ligament [24]. Therefore, to investigate the clinical significance of the expression of small amounts of neural elements in allografts, further research on the differences in proprioceptive function after remnantpreserving ACL reconstruction using allografts will be required.

As a limitation, the present study had a small sample size for determining satisfactory outcomes; however, since this was an experimental study, it was possible to perform experiments with a small sample size, and the limitation in detecting a difference was reduced by statistical analysis. We assessed only immunofluorescence analysis except for functional outcomes and sensory recoveries through the behavioural analysis of rats because the subjectivity of the experimenter could be involved. Additionally, because a functional evaluation was not performed, the sham operation consisting of only skin incision and closure was conducted on the left knee as a control; we considered that this simple procedure would not interfere with biomechanical loading and behaviour. As mentioned above, the lack of a biomechanical test was the major limitation of this study, but it might be thought to be observed in the form of partial integration or adhesion because the ACL was partially detached during surgery, and suture fixation was performed on the remnant tissue. Additionally, since the number of ACL samples collected from rats was too small and the slides were made with a thin thickness of $4 \mu \mathrm{m}$ in the course of the experiment, it might be difficult to definitively confirm the results of $\mathrm{H}$ and $\mathrm{E}$ staining. Finally, after the injection of NGF, the presence of neural cells was confirmed by immunofluorescence using an anti-nestin antibody, but it was not possible to confirm whether these nerve cells absolutely matched the mechanoreceptors.

\section{Conclusion}

The results from this study demonstrate that ACL remnants promote the new ingrowth and persistence of neural cells. We suggest that the ingrowth of neural elements can support the persistence and new ingrowth of mechanoreceptors and the functional stability of knee joints. However, the expression of neural cells in the Achilles allografts was lower than that in normal ACL and remnant ACL tissues in the quantitative evaluation.

\section{Abbreviations \\ ACL: Anterior cruciate ligament; NGF: Nerve growth factor; PBS: Phosphate- buffered saline; BSA: Bovine serum albumin; DAPI: 4,6-Diamidino-2- phenylindole}

\section{Acknowledgements}

This study was supported by a Wonkwang University research grant in 2020 . We also thank Hong Young Chun for assistance in quantitative analysis using ImageJ.

\section{Authors' contributions}

$\mathrm{CCH}$ designed and was a major contributor in this research. $\mathrm{LSH}, \mathrm{CHG}$, and CKC performed all the experiments and prepared the initial draft of the manuscript. SJS performed the data analysis and interpreted the data. All authors reviewed, edited, and approved the final content of the manuscript.

Funding

Not applicable

Availability of data and materials

The datasets used and analysed during the current study are available from the corresponding author upon reasonable request.

\section{Ethics approval}

This experimental study was approved by the Institutional Animal Care and Use Committee of Wonkwang University (WKU17-108). The procedures for animal experiments were in accordance with requirements in the

Declaration of Helsinki.

Consent for publication

This paper is approved by all authors for publication.

Competing interests

The authors declare that they have no competing interests. 


\section{Author details}

'Department of Orthopedic Surgery, Wonkwang University Hospital, 895, Muwang-Ro, Iksan 54538, South Korea. ${ }^{2}$ Department of Biological Sciences, College of Natural Sciences, Wonkwang University, Iksan, South Korea. ${ }^{3}$ Department of Orthopedic Surgery, Hankook Hospital, Mokpo, South Korea.

Received: 29 December 2019 Accepted: 14 July 2020

Published online: 23 July 2020

\section{References}

1. Bali K, Dhillon MS, Vasistha RK, Kakkar N, Chana R, Prabhakar S. Efficacy of immunohistological methods in detecting functionally viable mechanoreceptors in the remnant stumps of injured anterior cruciate ligaments and its clinical importance. Knee Surg Sports Traumatol Arthrosc. 2012:20:75-80

2. Hogervorst T, Brand RA. Mechanoreceptors in joint function. J Bone Joint Surg Am. 1998;80:1365-78.

3. Kim YK, Ahn JH, Yoo JD. A comparative study of clinical outcomes and second-look arthroscopic findings between remnant-preserving tibialis tendon allograft and hamstring tendon autograft in anterior cruciate ligament reconstruction: matched-pair design. Clin Orthop Surg. 2017;9: 424-31. https://doi.org/10.4055/cios.2017.9.4.424.

4. Ahn GY, Nam IH, Lee YH, Lee YS, Choi YD, Lee HH, et al. Factors affecting the extent of graft tendon synovialization after double-bundle anterior cruciate ligament reconstruction: based on second-look arthroscopic findings. Clin Orthop Surg. 2018;10(4):413-9. https://doi.org/10.4055/cios. 2018.10.4.413.

5. Lee BI, Min KD, Choi HS, Kwon SW, Chun DI, Yun ES, et al. Immunohistochemical study of mechanoreceptors in the tibial remnant of the ruptured anterior cruciate ligament in human knees. Knee Surg Sports Traumatol Arthrosc. 2009;17:1095-101.

6. Ochi M, Iwasa J, Uchio Y, Adachi N, Sumen $Y$. The regeneration of sensory neurones in the reconstruction of the anterior cruciate ligament. J Bone Joint Surg (Br). 1999;81:902-6.

7. Taketomi S, Inui H, Sanada T, Nakamura K, Yamagami R, Masuda H, et al. Remnant-preserving anterior cruciate ligament reconstruction using a threedimensional fluoroscopic navigation system. Knee Surg Relat Res. 2014;26: 168-76. https://doi.org/10.5792/ksrr.2014.26.3.168.

8. Barrack RL, Lund PJ, Munn BG, Wink C, Happel L. Evidence of reinnervation of free patellar tendon autograft used for anterior cruciate ligament reconstruction. Am J Sports Med. 1997;25:196-202.

9. Denti M, Monteleone M, Berardi A, Panni AS. Anterior cruciate ligament mechanoreceptors. Histologic studies on lesions and reconstruction. Clin Orthop Relat Res. 1994;308:29-32.

10. Kim SH, Chun $\mathrm{CH}$, Chun KC, Jo HJ, Kim KM. Histological assessment of mechanoreceptors in Achilles allografts after anterior cruciate ligament reconstruction. Am J Sports Med. 2012;40:2061-5. https://doi.org/10.1177/ 0363546512453303.

11. Doerks T, Copley RR, Schultz J, Ponting CP, Bork P. Systematic identification of novel protein domain families associated with nuclear functions. Genome Res. 2002;12:47-56.

12. Freeman MA, Wyke B. Articular contributions to limb muscle reflexes. The effects of partial neurectomy of the knee-joint on postural reflexes. $\mathrm{Br} J$ Surg. 1966;53:61-8

13. Nagai $K$, Araki D, Matsushita T, Nishizawa Y, Hoshino Y, Matsumoto T, et al. Biomechanical function of anterior cruciate ligament remnants: quantitative measurement with a 3-dimensional electromagnetic measurement system. Arthroscopy. 2016;32:1359-66.

14. Nakase J, Toratani T, Kosaka M, Ohashi Y, Tsuchiya H. Roles of ACL remnants in knee stability. Knee Surg Sports Traumatol Arthrosc. 2013;21:2101-6.

15. Dhillon MS, Bali K, Prabhakar S. Differences among mechanoreceptors in healthy and injured anterior cruciate ligaments and their clinical importance. Musc Ligaments Tendons J. 2012;2:38-43.

16. Dhillon MS, Bali K, Vasistha RK. Immunohistological evaluation of proprioceptive potential of the residual stump of injured anterior cruciate ligaments (ACL). Int Orthop. 2010;34:737-41.

17. Georgoulis AD, Pappa L, Moebius U, Malamou-Mitsi V, Pappa S, Papageorgiou CO, et al. The presence of proprioceptive mechanoreceptors in the remnants of the ruptured $A C L$ as a possible source of re-innervation of the ACL autograft. Knee Surg Sports Traumatol Arthrosc. 2001;9:364-8.
18. Ochi M, Adachi N, Deie M, Kanaya A. Anterior cruciate ligament augmentation procedure with a 1-incision technique: anteromedial bundle or posterolateral bundle reconstruction. Arthroscopy. 2006;22:463.e1-5.

19. Chun $\mathrm{CH}$, Han HJ, Lee BC, Kim DC, Yang JH. Histologic findings of anterior cruciate ligament reconstruction with Achilles allograft. Clin Orthop Relat Res. 2004;421:273-6.

20. Chun KC, Lee SH, Kim JW, Jin EJ, Kim KM, Chun CH. Immunohistochemical and immunocytochemical study of mechanoreceptors in anterior cruciate ligament reconstruction with the remnant-preserving technique using Achilles tendon allografts. J Orthop Surg Res. 2017;12:93. https://doi.org/10. 1186/s13018-017-0593-0.

21. Mammoto T, Seerattan RA, Paulson KD, Leonard CA, Bray RC, Salo PT. Nerve growth factor improves ligament healing. J Orthop Res. 2008:26:957-64.

22. Song GY, Zhang H, Zhang J, Li X, Chen XZ, Li Y, et al. The anterior cruciate ligament remnant: to leave it or not? Arthroscopy. 2013;29(7):1253-62.

23. Papalia R, Franceschi F, Vasta S, Di Martino A, Maffulli N, Denaro V. Sparing the anterior cruciate ligament remnant: is it worth the hassle? Br Med Bull. 2012;104:91-111.

24. Feng SM, Maffulli N, Oliva F, Wang AG, Sun QQ. Arthroscopic remnantpreserving anterior talofibular ligament reconstruction does not improve mid-term function in chronic ankle instability. Injury. 2020;50020-1383(20): 30413-7.

\section{Publisher's Note}

Springer Nature remains neutral with regard to jurisdictional claims in published maps and institutional affiliations.
Ready to submit your research? Choose BMC and benefit from:

- fast, convenient online submission

- thorough peer review by experienced researchers in your field

- rapid publication on acceptance

- support for research data, including large and complex data types

- gold Open Access which fosters wider collaboration and increased citations

- maximum visibility for your research: over $100 \mathrm{M}$ website views per year

At BMC, research is always in progress.

Learn more biomedcentral.com/submissions 